\title{
Borane-Tetrahydrofurane Complex Reduction of Nickel and First Transition Metals in Tetrahydrofurane Media: Controllable Chemistry Leading to Nanoscale Metal and Metal Boride Particles
}

\author{
Delicia Acosta*, Elio E. Gonzo, Hugo A. Destéfanis \\ Instituto de Investigaciones para la Industria Química - INIQUI-CONICET ANPCYT, Consejo de Investigaciones- \\ CIUNSa, Facultad de Ingeniería-UNSa, Buenos Aires, Argentina \\ Email: "acostad@unsa.edu.ar
}

Received 10 November 2015; accepted 10 January 2016; published 13 January 2016

Copyright @ 2016 by authors and Scientific Research Publishing Inc.

This work is licensed under the Creative Commons Attribution International License (CC BY). http://creativecommons.org/licenses/by/4.0/

\section{(c) (7) Open Access}

\begin{abstract}
Nickel borides doped with transition metal ( $\mathrm{Cr}, \mathrm{Mn}, \mathrm{Fe}, \mathrm{Co}, \mathrm{Cu}$, and $\mathrm{Zn}$ ) $\mathrm{MNiB}, 4 \% \mathrm{w} / \mathrm{w}$ respect to $\mathrm{Ni}$ were prepared by chemical reduction of nickel and metallic salts in methanol solution with borane-tetrahydrofurane $\left(\mathrm{BH}_{3}\right.$-THF) complex obtained in aprotic solvent (THF anhydrous). Different techniques were used to characterize these materials. The MNiB amorphous structure was verified by XRD. Thermal treatment in $\mathrm{N}_{2}$ shows $\mathrm{Ni}^{\circ}, \mathrm{Ni}_{2}$ Band $\mathrm{NiO}$ phases. Spongy-morphology was evident by SEM studies in all cases. XPS and TEM show that doped and non-doped nickel boride was present as $\mathrm{Ni}^{\circ}$ in metallic state as principal phase and nickel alloying with boron was observed in minor quantities. The oxidation stability, magnetic susceptibility and catalytic effect are correlated with parameters of each dopant metal.
\end{abstract}

Keywords

NiB, Doped NiB, Borane-Tetrahydrofurane Reduction, Catalyst

\section{Introduction}

It has been known for a long time that it is possible to precipitate black amorphous solids from solutions con${ }^{*}$ Corresponding author.

How to cite this paper: Acosta, D., Gonzo, E.E. and Destéfanis, H.A. (2016) Borane-Tetrahydrofurane Complex Reduction of Nickel and First Transition Metals in Tetrahydrofurane Media: Controllable Chemistry Leading to Nanoscale Metal and Metal Boride Particles. Modern Research in Catalysis, 5, 19-30. http://dx.doi.org/10.4236/mrc.2016.51003 
taining nickel by adding sodium or lithium borohydride [1]. The chemistry of the process is however not well understood. As a result, the literature is replete with various recipes for powder preparation given rise to products of varying nature and composition. These precipitates are considered to exhibit catalytic activity in all kinds of reduction reactions [2]. Although their composition remained unclear for 40 years, their annealing behavior was investigated and found to lead to crystalline $\mathrm{Ni}_{2} \mathrm{~B}$ [3] or $\mathrm{Ni}_{3} \mathrm{~B}$ and elemental nickel $\left(\mathrm{Ni}^{\circ}\right)$ at temperatures near $773 \mathrm{~K}$. In this report, reaction steps leading to the formation of fine powders of nickel, and nickel borides are reported. Nickel boride (NiB) and nickel metal dopants boride (MNiB) amorphous catalysts were prepared following a previously reported technique [4].

On the other hand in previous reports [5], nickel borides doped with first transition metal proved active catalysts in hydrogenation reactions like Glucose and Nitrobenzene hydrogenations according to the electrical nature of the metal dopant. Moreover the incorporation of the dopant metals in minor proportions species shows that the obtained boride is unchanged in morphology and composition.

\section{Experimental}

\subsection{Preparation}

A reducing solution corresponding to the complex diborane-tetrahydrofurane $\left(\mathrm{BH}_{3}-\mathrm{THF}\right)$ was obtained by reacting $1 \mathrm{~g}$ of $\mathrm{NaBH}_{4}$ (Aldrich, 99+\%) with $1 \mathrm{ml}$ of $\mathrm{H}_{2} \mathrm{O}$ in $100 \mathrm{ml}$ of THF (Mallinckrodt) at $25^{\circ} \mathrm{C}$. This solution was used to reduce the metallic salts ( $\mathrm{Ni}, \mathrm{Cr}, \mathrm{Mn}, \mathrm{Fe}, \mathrm{Co}, \mathrm{Cu}, \mathrm{Zn})$ in methanol (anhydrous) solution, in necessary quantities to obtain $4 \mathrm{w} / \mathrm{w} \%$ proportions of dopants metal over nickel, were added drop wise over $\mathrm{BH}_{3}-$ THF solution with vigorous stirring. All the black powder material obtained by this way was used "as-prepared" in catalytic tests.

For characterization purposes the black precipitate was filtered immediately and washed with several amounts of water and THF to remove sodium acetate (a by-product) and non-reacted sodium borohydride and finally dried in vacuum at $323 \mathrm{~K}$.

\subsection{Characterization}

The contents of dopants metals and nickel in metal-nickel-borides were analyzed by Atomic Absorption spectroscopy in a GBC 904 AA. Boron contents were simultaneously analyzed as Boric acid and by Azometin $\mathrm{H}$ molecular absorption technique. BET surface area was measured by $\mathrm{N}_{2}$ adsorption at $77^{\circ} \mathrm{K}$ in a Micromeritic Flow Sorb Model 2 - 2300. X-Ray Diffraction pattern was obtained on a Rigaku D max-IIC with Cu $\mathrm{K}_{\alpha}$ radiation $(\mathrm{V}=40 \mathrm{kV}, \mathrm{I}=20 \mathrm{~mA})$ and Ni filter at a scanning rate of $2^{\circ} / \mathrm{min}$. For Thermal Treatment studies, the sample was annealed at $500^{\circ} \mathrm{C}$ under $\mathrm{N}_{2}$ flow during $3 \mathrm{~h}$. Thermo gravimetric TG and DTA studies were carried out in a RIGAKU unit at heating rate of $10^{\circ} \mathrm{C} / \mathrm{min}$ in air. The surface morphology was observed by scanning electron microscopy (SEM; JEOL-JSM-15610LV at $10 \mathrm{kV}$ ). Particle size and morphology shape of the powders were examined by transmission electron microscopy (TEM) and the corresponding selected area electro diffraction (SAED) in a PHILIPS CM200 microscope at an accelerating voltage of $200 \mathrm{kV}$. FTIR studies were carried out in a Bruker IFS 88B on samples dispersed in KBr. Infrared spectra was recorded ranging 4000 to $800 \mathrm{~cm}^{-1}$. XPS analyses were performed in a multi-technique system (SPECS) equipped with a dual $\mathrm{Mg} / \mathrm{Al} \mathrm{X-ray} \mathrm{source}$ and a hemispherical PHOIBOS 150 analyzer operating in the fixed analyzer transmission (FAT) mode. The spectra were obtained with pass energy of $30 \mathrm{eV}$; a $\mathrm{Mg}-\mathrm{K}_{\alpha} \mathrm{X}$-ray source was operated at $100 \mathrm{~W}$ and $10 \mathrm{kV}$. The working pressure in the analyzing chamber was less than $7 \times 10^{-9}$ mbar.

Volumetric Magnetic Susceptibility for doped and non-doped nickel borides were measured using a Gouy balance at room temperature. Experimental data of volumetric magnetic susceptibility are obtained measuring the resultant magnetic force that acts when a powder sample is placed in a known magnetic field. The analytical balance has sensibility of $50 \times 10^{-7}$ Newton.

\subsection{Catalytic Test}

The total number of accessible surface active sites on the catalyst was determined by means of hydrogen selective chemisorption. The catalyst, after reaction, was washed with ethanol, dried in $\mathrm{He}$ at $323 \mathrm{~K}$ followed by evacuation at $473 \mathrm{~K}$ for 3 hours. The hydrogen isotherms were measured at $323 \mathrm{~K}$. The amount of hydrogen chemisorbed was evaluated from extrapolation of the isotherm at zero pressure. 
Glucose hydrogenation: Liquid phase hydrogenation of glucose was performed at $343 \mathrm{~K}$ and $5.0 \mathrm{MPa}$ in a stainless steel batch reactor, which contained $2.0 \mathrm{~g}$ of "as-prepared" catalyst and $0.250 \mathrm{~L}$ of glucose aqueous solution. During the hydrogenation, the reaction mixture was stirred vigorously at $1000 \mathrm{rpm}$ to eliminate transport effects. D (+) Glucose (Merck) $(0.5 \mathrm{M})$ aqueous solution at $\mathrm{pH}=6$ was used in all cases. A $3 \mathrm{wt} \% \mathrm{Ni} /$ glucose solution ratio was used. The experiments were carried out under identical conditions to those reported by Acosta et al. [6]. Glucose consumption was followed by a colorimetric method using a specific enzymatic test.

Nitrobenzene hydrogenation: The liquid phase nitrobenzene hydrogenation was carried out in a shaker Parr 3911 Model reactor under constant total pressure. "As-prepared” catalyst samples, not dried, were used. Nitrobenzene (Mallinckrodt) $1 \mathrm{M}$ in methanol and catalyst concentration of nickel $0.1 \mathrm{~mol} / \mathrm{L}$ was used in a $0.250 \mathrm{~L}$ of mixed solution.

The air in the reaction systems was removed, prior to reaction, using hydrogen at room temperature. In all cases the system was heated up to reaction temperature and then pressurized.

\section{Proposed Reaction Step to Obtain Nickel Boride}

All the samples were prepared following the same methodology using the reducing complex agent. The reducing solution corresponding to the complex borane-tetrahydrofurane $\left(\mathrm{BH}_{3}-\mathrm{THF}\right)$ was obtained from $\mathrm{NaBH}_{4}$ with water in stoichometry quantities in tetrahydrofurane medium, according to the following reaction Equations (1) and (2).

$$
\begin{aligned}
& \mathrm{NaBH}_{4}(\mathrm{c})+\mathrm{H}_{2} \mathrm{O} \rightleftharpoons \mathrm{BH}_{3}(\mathrm{~g})+\mathrm{H}_{2}(\mathrm{~g})+\mathrm{NaOH}(\mathrm{s}) \\
& \mathrm{BH}_{3}(\mathrm{~g})+\mathrm{THF}(1) \rightleftharpoons \mathrm{BH}_{3}: \operatorname{THF}(1)
\end{aligned}
$$

$\mathrm{BH}_{3}$-THF stability was demonstrated by Hopps et al. [7] and Brown et al. [8]. The formation of metallic borides from reduction of metallic salts using as reducer agent $\mathrm{BH}_{3}$-THF is a complex process, which has not even been elucidated totally yet. In this contribution a mechanism to obtain nickel boride is presented. To analyze the possible reaction mechanism it is considered first that reducer complex $\left(\mathrm{BH}_{3}\right.$-THF) interaction only happens with nickel salt and there is not reaction with solvent. This hypothesis was verified experimentally and there is not reaction between the methanol and $\mathrm{BH}_{3}$-THFcomplex.

All borides preparations were made allowing borane-tetrahydrofurane $\left(\mathrm{BH}_{3}-\mathrm{THF}\right)$ complex reduce to $\mathrm{Ni}$ and dopant metal, $\mathrm{M}$ : (Cr, or $\mathrm{Co}$, or $\mathrm{Cu}$, or Fe, or $\mathrm{Mn}$, or $\mathrm{Zn}$ ) ions in THF media. Reducing scheme to obtain products can be formulated in the following reaction steps.

First reaction step. A metathesis reaction of $\mathrm{NiCl}_{2}$ with $\mathrm{BH}_{3}$ produce metal hydride, as it is shown in equation (3).

$$
3 \mathrm{NiCl}_{2}+2 \mathrm{BH}_{3} \rightarrow 3 \mathrm{NiH}_{2}(\mathrm{~g})+2 \mathrm{BCl}_{3}
$$

Enthalpy of reaction step 3 can be calculated from references data on Table 1.

$$
\Delta \mathrm{H}_{\mathrm{R}(3)}^{0}=-835,57 \mathrm{kcal} / \mathrm{mol}
$$

Second reaction step. Nickel hydride can react with borane, in accordance with the reaction 4 , forming a borohydride salt of nickel hydride. Step 4 is possible due to $\mathrm{BH}_{3}$ is a Lewis acid that reacts with a Lewis base, $\mathrm{H}^{-}$ to form $\mathrm{BH}_{4}^{-}$complex and an ion nickel hydride.

$$
\mathrm{NiH}_{2}(\mathrm{~s})+\mathrm{BH}_{3}(\mathrm{sol}) \rightarrow \mathrm{NiH}^{+} \mathrm{BH}_{4}^{-}(\mathrm{s})
$$

Enthalpy of formation in Equation (4) can be calculated from the data on Table 1 and the net energy of $\mathrm{NiH}^{+}$ $\mathrm{BH}_{4}^{-}$can be estimated using a simple ionic model. For that calculation a structure like CsCl was adopted according to their similar ionic ratio. The Madelung constant value was 1.76267, Born exponent was assumed 12 equal to $\mathrm{Cs}$ ion and $\mathrm{NiH}^{+}$radius of $0.7805^{\circ} \mathrm{A}$ [9]. According to this data the net energy $\mathrm{NiH}^{+} \mathrm{BH}_{4}^{-}$value was $-341.22 \mathrm{kcal} / \mathrm{mol}$. Total enthalpy of step 4) can be calculated using net energy and reference values in Table 1.

$$
\Delta \mathrm{H}_{\mathrm{R}(\mathrm{b})}^{0}=-65.96 \mathrm{Kcal} / \mathrm{mol}
$$

Third reaction step. Decomposition of the $\mathrm{NiH}^{+} \mathrm{BH}_{4}^{-}$in $\mathrm{NiB}$ and $\mathrm{H}_{2}$ according to the reaction 5 .

$$
\mathrm{NiH}^{+} \mathrm{BH}_{4}^{-}(\mathrm{s}) \rightarrow \mathrm{NiB}(\mathrm{s})+5 / 2(\mathrm{~g})
$$


Table 1. Enthalpy of formation on substances including in mechanism proposed to obtain nickel boride.

\begin{tabular}{cc}
\hline Substance & $\Delta \mathrm{H}^{\circ} \mathrm{f}(\mathrm{kcal} / \mathrm{mol})$ \\
\hline $\mathrm{NiCl}_{2}$ & $-75,95 \mathrm{a})$ \\
$\mathrm{BCl}_{3}$ & $-96,40 \mathrm{a})$ \\
$\mathrm{B}_{2} \mathrm{H}_{6}$ & $8,612 \mathrm{a})$ \\
$\mathrm{NiH}_{2}$ & $-283,9 \mathrm{~b})$ \\
$\mathrm{NiH}^{+}$ & $-35,7 \mathrm{c})$ \\
$\mathrm{Ni}_{2} \mathrm{~B}$ & $-67,27 \mathrm{~d})$ \\
$\mathrm{Ni}_{4} \mathrm{~B}_{3}$ & $-231,93 \mathrm{~d})$ \\
$\mathrm{NiB}$ & $-82,14 \mathrm{~d})$ \\
\hline
\end{tabular}

a) Data from Schlegel reference [10]; b) Data calculated from Born-Haber in our work; c) Data from reference [9]; d) Data from Gordienko reference [17].

The enthalpy of this reaction can be calculated from the data of Table 1. For the NiB the enthalpy of formation was: $\Delta \mathrm{H}_{f(\text { Ic })}^{0}=-261.84 \mathrm{Kcal} / \mathrm{mol}$

Nickel boride scheme of reaction steps: Global stoichiometry for NiB as product is shown in Equation (6). It was obtained using 3, 4 and 5 reactions step.

$$
3 \mathrm{NiCl}_{2}+5 \mathrm{BH}_{3} \rightarrow 3 \mathrm{NiB}(\mathrm{g})+2 \mathrm{BCl}_{3}+7.5 \mathrm{H}_{2}
$$

The global enthalpy of the process in reaction step 6 can be calculated from those obtained for 3 , 4, and 5 steps:

$$
\Delta \mathrm{H}_{\mathrm{R}(5)}^{0}=-1818.84 \mathrm{kcal} / \mathrm{mol}
$$

This value shows the thermodynamic feasibility of the proposed mechanism. Different stoichiometry of nickel borides can be calculated using the same methodology. Chemical reactions that help explain the formation of metallic nickel and $\mathrm{NiB}_{2}$ are summarized in Scheme 1 and Scheme 2.

$$
\begin{gathered}
2\left(\mathrm{NiH}^{+}+\mathrm{e}^{-} \rightarrow \mathrm{Ni}^{0}+1 / 2 \mathrm{H}_{2}\right) \\
\frac{2\left(\mathrm{BH}_{4}^{-} \rightarrow \mathrm{B}^{0}+2 \mathrm{H}_{2}+\mathrm{e}^{-}\right)}{2 \mathrm{NiH}^{+} \mathrm{BH}_{4}^{-} \rightarrow \mathrm{NiB}_{2}+\mathrm{Ni}^{0}+5 \mathrm{H}_{2}}
\end{gathered}
$$

Scheme 1. Scheme obtaining metallic nickel and nickel boride from nickel hydride borohydride.

Reaction step 7) can be summarized with 3) and 4) steps to obtain global reaction 8)

$$
\begin{aligned}
& 3\left(\mathrm{NiCl}_{2}+5 \mathrm{BH}_{3} \rightarrow 3 \mathrm{NiH}^{+} \mathrm{BH}_{4}^{-}(\mathrm{s})+2 \mathrm{BCl}_{3}\right) \\
& \frac{3\left(2 \mathrm{NiH}^{+} \mathrm{BH}_{4}^{-} \rightarrow \mathrm{NiB}_{2}+\mathrm{Ni}^{0}+5 \mathrm{H}_{2}\right)}{\mathbf{6 N i C l}_{2}+\mathbf{1 0 B H}_{3} \rightarrow \mathbf{3} \mathbf{N i B}_{2}+\mathbf{3} \mathbf{N i}^{\mathbf{0}}+\mathbf{1 5 H}_{2}+\mathbf{4} \mathbf{B C l}_{3}}
\end{aligned}
$$

Scheme 2. Global reaction to obtain $\mathrm{Ni}$ and $\mathrm{NiB}$ from $\mathrm{NiCl}_{2}$ and $\mathrm{BH}_{3}$.

According to global reaction 8), it is possible to obtain nickel metal and nickel boride as primary products. The mechanism of formation of these materials in Scheme 1 and Scheme 2 implies that once the reduction of $\mathrm{Ni}^{2+}$ to $\mathrm{Ni}^{\circ}$ takes place, $\mathrm{BH}_{3}$ can chemisorbs on metallic nickel (see Scheme 3). Immediately, a decomposition process of $\mathrm{BH}_{3}$ starts due to metal acts as catalyst. This reaction allows to obtain different rate of Ni/B and hydrogen as products, as can be seen in Scheme 3. 


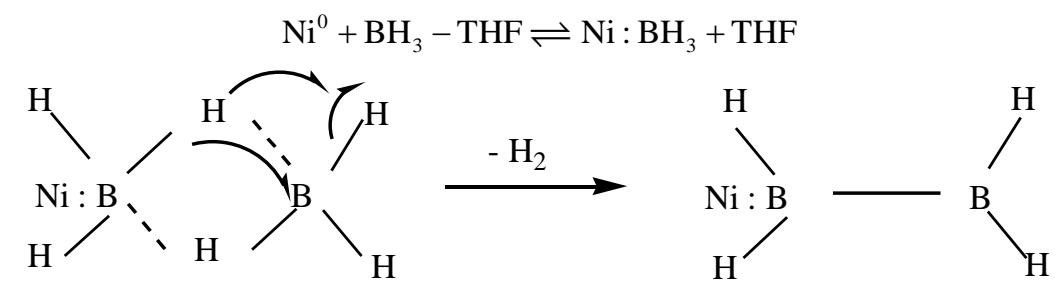

Scheme 3. Borane chemisorption over metallic nickel allows B-B bond formation.

The process follows a similar mechanism to the transformation of $\mathrm{B}_{2} \mathrm{H}_{6}$ in species of borane with higher rate of $\mathrm{B} / \mathrm{H}$. It conduces to higher B-B bonding and hydrogen generation, just as it is shown in the following Scheme 4:

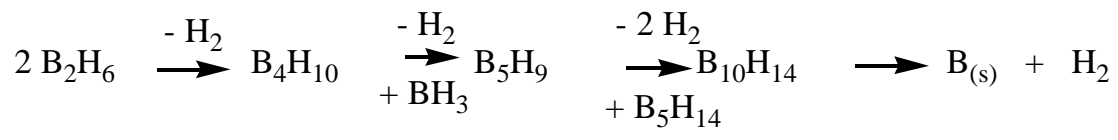

Scheme 4. Higher B-B bond formation.

The structure of the tetraborane represented in Scheme 5, according to the Lipscomb [11] method shows the formation of B-B bonding that then continues being formed as the evolution lapses toward the most stable species $\mathrm{B}(\mathrm{s})$ and $\mathrm{H}_{2}$.

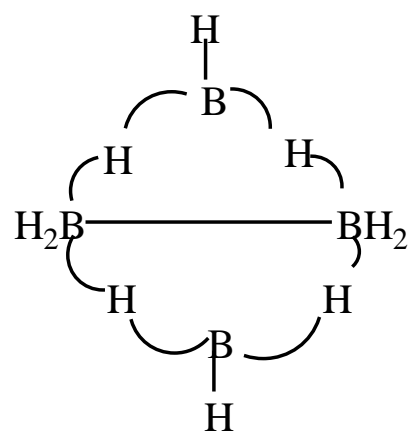

Scheme 5. Tetraborane structure according to Lipscom [11] method.

According to reports [11] the hydrolysis of borohydride depends on the metal surface become amorphous, which generates a highly under-coordinated metal atoms at the surface that leads to electron-rich structure. However Zhijie $\mathrm{Wu}$ [12] reports relates to the hydrolysis of borohydride in aqueous medium in the presence of an alkaline medium and in our work we mean the action of $\mathrm{BH}_{3}$ generated in a no aqueous medium (THF). For this study the $\mathrm{NiB}_{2}$ and the bimetallic borides (MNiB) could be classify by the relation boron-metal in the metallic borides where the $\mathrm{B}$ forms a net of $\mathrm{B}-\mathrm{B}$ bonds which gives place to a net produced by metal-metal bonds (Figure 1). In this kind of boride the interactions boron-metal are week, so the metallic net could be considered as an independent alloy of B.

\section{Results and Discussion}

After metallic salts (Ni, Cr, Co, $\mathrm{Cu}, \mathrm{Fe}, \mathrm{Mn}, \mathrm{Zn}$ ) were allow to react with $\mathrm{BH}_{3}$ :THF complex, in all cases a black precipitate was obtained from the reaction mixture. Solid was filtered immediately and washed with small amounts of water and methanol to remove sodium acetate and non-reacted $\mathrm{NaBH}_{4}$, in order to analyze their composition. The chemical analysis show that bulk composition were formulated as (M + Ni) B2 (Table 2) when $\mathrm{Cr}$, Co and $\mathrm{Cu}$ were used as metal dopant. Rate of $\mathrm{B} /(\mathrm{M}+\mathrm{Ni})$ increased when $\mathrm{Mn}, \mathrm{Zn}$ and Fe were used, due to their feasibility to oxidation process in atmospheric drying and the feasibility to obtain higher B-B bond as was shown in Scheme 3. It was found that dopants metal loading were the same than the theoretical value (3.8 4 w/w\%) for Co, $\mathrm{Cu}, \mathrm{Fe}, \mathrm{Mn}$ and Zn (see Table 2). 


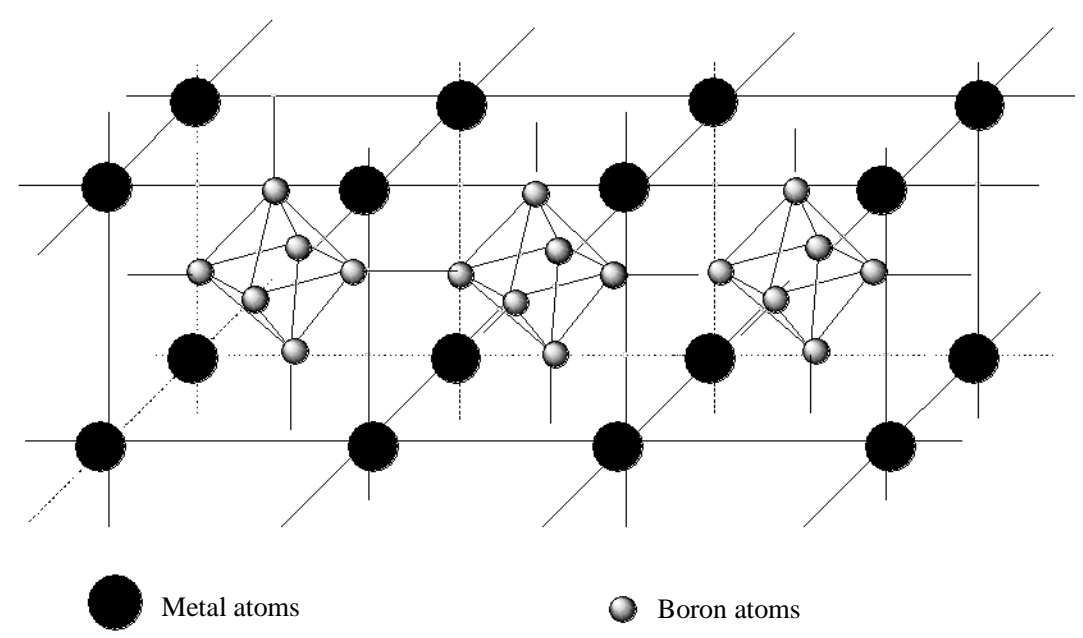

Figure 1. Structure of metal boride type $\mathrm{MB}_{2}$ and higher $\mathrm{MB}_{\mathrm{n}}$.

Table 2. Characterization results on $\mathrm{NiB}$ and $\mathrm{MNiB}$.

\begin{tabular}{|c|c|c|c|c|c|c|c|c|}
\hline \multirow{2}{*}{$\begin{array}{l}\text { Chemical } \\
\text { Analysis }\end{array}$} & \multirow{2}{*}{$\begin{array}{c}\mathrm{S}_{\mathrm{BET}} \\
\left(\mathrm{m}^{2} / \mathrm{g}\right)\end{array}$} & \multirow{2}{*}{$\begin{array}{c}\mathrm{S}_{\text {MET. }} \\
\left(\mathrm{m}^{2} / \mathrm{g}\right) 10^{6}\end{array}$} & \multirow{2}{*}{$\begin{array}{l}\text { Susceptibility } \\
10^{8} \mathrm{emu} \cdot \mathrm{g}^{-1}\end{array}$} & \multirow{2}{*}{$\begin{array}{c}\text { TG Exothermic } \\
\text { peak K }\end{array}$} & \multicolumn{2}{|c|}{ Glucose } & \multicolumn{2}{|c|}{ NitroBenzene } \\
\hline & & & & & $\begin{array}{c}\mathbf{k}_{\mathrm{MNiB}} 10^{3} \\
(1 / \mathrm{min})^{\mathrm{a}}\end{array}$ & $\begin{array}{l}\text { TOF } \\
\left(\mathrm{s}^{-1}\right)^{\mathrm{c}}\end{array}$ & $\begin{array}{c}\mathbf{k}_{\mathrm{MNiB}} 10^{4} \\
(1 / \mathrm{min})^{\mathrm{b}}\end{array}$ & $\begin{array}{l}\text { TOF } \\
\left(\mathrm{s}^{-1}\right)^{\mathrm{c}}\end{array}$ \\
\hline $\mathrm{B}_{2} \mathrm{NiCr}_{0,01}$ & 19 & 3.12 & 14.60 & 1081 & 19.45 & 0.81 & 2.99 & 0.0274 \\
\hline $\mathrm{B}_{4} \mathrm{NiMn}_{0,03}$ & 2 & 2.32 & 10.16 & 1031 & 5.7 & 0.32 & 0.218 & 0.00027 \\
\hline $\mathbf{B}_{3} \mathrm{NiFe}_{0,03}$ & 21 & 0.42 & 9.544 & 1018 & 8.6 & 0.27 & 0.218 & 0.00148 \\
\hline $\mathrm{B}_{2} \mathrm{NiCo}_{0.04}$ & 14 & & 13.03 & 1048 & 9.81 & & 0.545 & \\
\hline $\mathrm{B}_{2} \mathrm{Ni}$ & 10 & 3.13 & 7.255 & 949 & 6.77 & 0.28 & 1.36 & 0.0124 \\
\hline $\mathrm{B}_{2} \mathrm{NiCu}_{0,04}$ & 14 & 1.09 & 11.17 & 1006 & 9.1 & 1.08 & 1.09 & 0.0285 \\
\hline $\mathrm{B}_{3} \mathrm{NiZn}_{0,04}$ & 14 & 2.64 & 7.006 & 974 & 5.6 & 0.28 & 0.136 & $2.56 \mathrm{E}-05$ \\
\hline
\end{tabular}

a) Initial rate to $343 \mathrm{~K}, 5 \mathrm{MPa} \mathrm{H}_{2}$, 3\% wt/wt Cat/Glucose, $4 \% \mathrm{wt} / \mathrm{wt}$ Dopant/Ni. b) Initial rate to $328 \mathrm{~K}, 0.374 \mathrm{MPa} \mathrm{H}_{2}$, 3\% wt/wt Cat/Nitrobenzene, $4 \%$ $\mathrm{wt} / \mathrm{wt}$ Dopant/Ni; c) Turnover number (TOF) glucose or nitrobenzene/ active site of catalyst.

\subsection{Thermo-Gravimetric Results}

The thermo gravimetric analysis of doped and non-doped nickel-borides shows the loss of weight by the elimination of THF and methanol solvents through an endothermic process that occurs at about $473 \mathrm{~K}$. In the temperature range $973 \mathrm{~K}$ - $1083 \mathrm{~K}$, a single exothermic peak appears due to the formation of metal borate by the presence of air in the thermo-gravimetric experience. This effect was corroborated by DRX and FTIR. The difference found between DTA results obtained over doped and non-doped borides is the temperature of the exothermic process as can be seen in Table 2. The metal borate phase seems to be more stable when chromium was used as dopant metal.

\subsection{Scanning Electron Microscopy}

The sponge-like morphology of all the samples could be attributed to the high hydrogen production during its preparation (Figure 2). It could be a consequence of metallic ion reduction reaction by the $\mathrm{BH}_{3}$-THF complex that produces metal borides. This was also observed by Xie et al. [13], comparing the surface topology of $\mathrm{Ni}^{2+}$ over the silica, after the addition of $\mathrm{BH}_{4}^{-}$to obtain NiB. We agree with Xie et al. [13], who considered that the spongy aspect is due to the fact that the solid is constituted by thousands of very tiny particles with an average size around $300 \mathrm{~nm}$. Also, Kapfenberger [14] observed in SEM micrographs the presence of nanometric characteristic particles, with narrow size distribution and diameter about $50 \mathrm{~nm}$. The micrographs also show light colored 


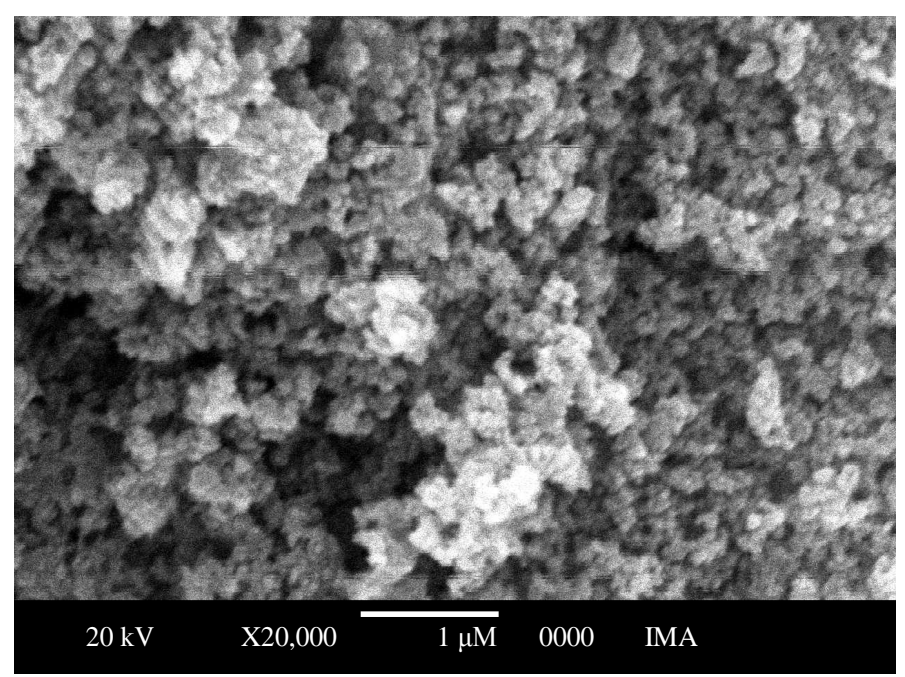

Figure 2. SEM micrograph of nickel boride.

particles corresponding to the starting oxidation process that appears when the dry sample is exposed to air.

If the precipitate from the reaction was isolated under ambient conditions, a stable light green powder was obtained which upon heat processing and XRD analysis indicated a mixture of metallic Ni and nickel oxide. Atmospheric condition allows oxidation process due to oxidation potential as can be seen in Scheme 6 .

Metallic nickel produces $\mathrm{NiO}$ in atmospheric condition while boron in same conditions yielded higher boron oxides and boric acid than $\mathrm{Ni}^{\circ}$ oxidation. Similar behavior was reported by Glavee [3].

For Nickel

$2 \mathrm{Ni}^{0}+\mathrm{nH}_{2} \mathrm{O}+1 / 2 \mathrm{O}_{2} \rightarrow 2 \mathrm{Ni}(\mathrm{OH})_{\mathrm{n}} \quad \Delta \mathrm{E}=1.529$ volt

For Boron

$2 \mathrm{~B}^{0}+3 \mathrm{H}_{2} \mathrm{O}+3 / 2 \mathrm{O}_{2} \rightarrow 2 \mathrm{BO}_{3} \mathrm{H}_{3} \quad \Delta \mathrm{E}=2.029$ volt

Scheme 6. Oxidation process for Nickel and Boron in atmospheric condition.

Light colored particles composition was confirmed by FTIR and DRX after sample calcinations at $1073 \mathrm{~K}$. Moreover, in DRX profiles of calcinated samples a borate phases (full oxidation process) is the predominant species. In minor quantities nickel boride, nickel oxide and metallic nickel are obtained. The FTIR studies on the same samples show, as in DRX, borates and $\mathrm{NiO}$ characteristic vibration bands. The vibration stretching band of B-O at $1350 \mathrm{~cm}^{-1}$ is followed by an asymmetric vibration B-O-B at $1375 \mathrm{~cm}^{-1}$ which is confirmed with the symmetric stretching B-O-B at $1260 \mathrm{~cm}^{-1}$. The absorption band at $1500 \mathrm{~cm}^{-1}$ could be attributed to the NiB because it does not belong to nickel oxide or borate.

\subsection{X-Ray Diffraction}

X-Ray Diffraction studies performed on doped and non-doped nickel borides show amorphous structures in all cases. Only one broad peak around $2 \theta=45^{\circ}$ was observed for the fresh sample indicating a typical amorphous character [13]. The nickel boride profile is consistent with the structure of mixtures of $\mathrm{Ni}_{2} \mathrm{~B}$ and $\mathrm{Ni}$, according to Kapfenberger et al. [14]. To study where phases are present in amorphous alloy is necessary to anneal solids.

Thermal Treatment: Thermal treatment of doped and non-doped nickel borides samples were carried out to study the phase's transformation. The heating rate was $2^{\circ} \mathrm{C} / \mathrm{min}$ up to $773 \mathrm{~K}$ in $\mathrm{N}_{2}$ atmosphere. With the increase of treating temperature the broad peak around $2 \theta=45^{\circ}$ became sharper and several other crystallite diffraction peaks corresponding to metallic nickel appear indicating the occurrence of crystallization processes accompanying decomposition of Ni-B alloy (see Figure 3). During washing procedure NiO phase appears due to surface oxidation process. As well as in SEM analysis the proportion of $\mathrm{NiO}$ and $\mathrm{Ni}^{\circ}$ phases depends upon dopant metal. 
Sample Name: BNi-DOPADO

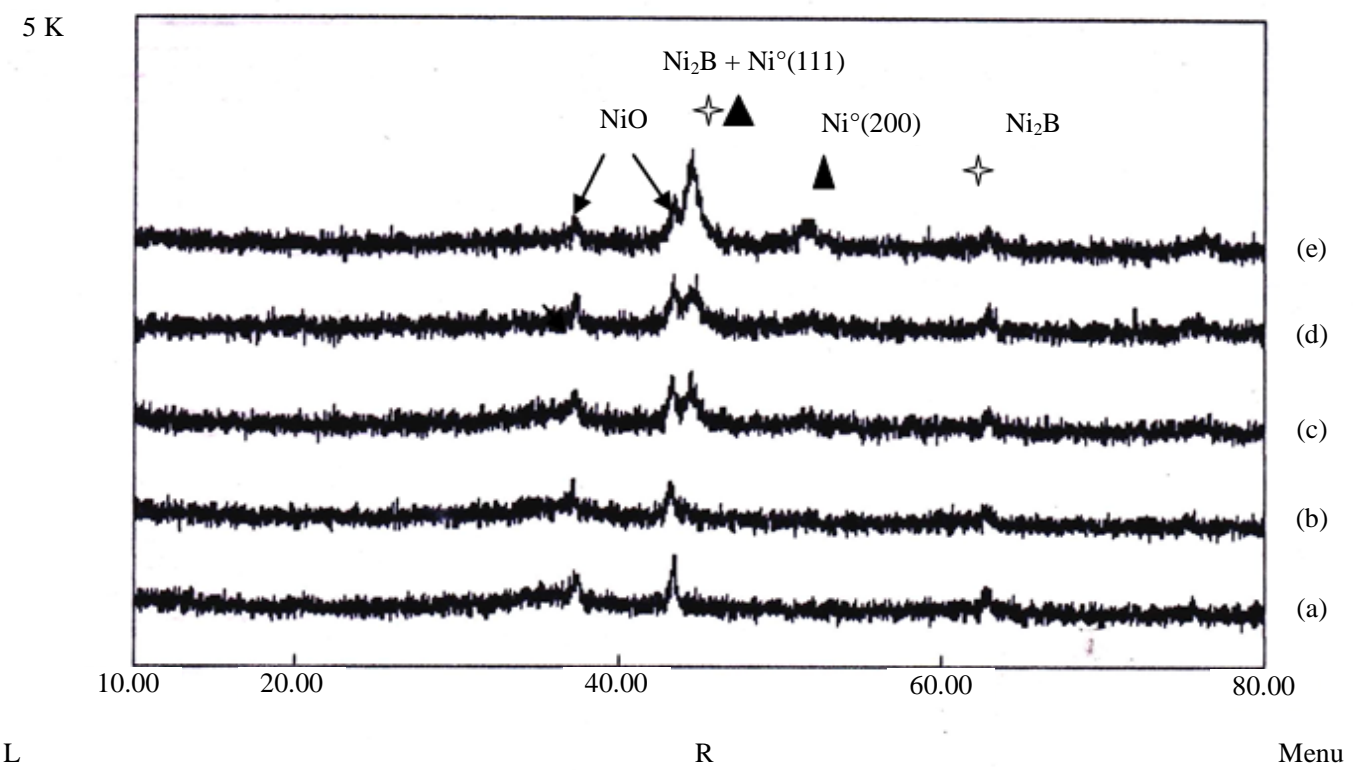

Figure 3. $\mathrm{XRD}$ at $773 \mathrm{~K}$ in $\mathrm{N}_{2}$ atmosphere of: (a) $\mathrm{ZnNiB}$, (b) $\mathrm{MnNiB}$, (c) $\mathrm{NiB}$, (d) $\mathrm{CoNiB}$, (e) $\mathrm{CrNiB}$.

\subsection{XPS Analysis}

For the fresh sample (not annealed), almost all the nickel species were present in the metallic state, corresponding to the binding energy of $856.4 \mathrm{eV}$ in $\mathrm{Ni} 2 \mathrm{p}_{3 / 2}$ level, as can be seen in Figure 4 . The boron species were present in both the alloying state with $\mathrm{Ni}$ and the oxidized state corresponding to $\mathrm{BE}$ of 188.3 and $192.2 \mathrm{eV}$, respectively. Since the BE of alloying B was nearly $1.0 \mathrm{eV}$ higher than that of the standard pure B $187.1 \mathrm{eV}$ [15], one can conclude that partial electron transfer occurred from $\mathrm{B}$ to $\mathrm{Ni}$ in Ni-B amorphous alloy, making $\mathrm{Ni}$ electron-enriched, although no significant change in the BE of the metallic Ni alloying with B was observed, due to the much larger size of the $\mathrm{Ni}$ atom in comparison with that of $\mathrm{B}$ atom. In doped and non-doped nickel borides the signal corresponding to Ni-B binding energy was lower than $\mathrm{B}_{2} \mathrm{O}_{3}$ signal. It is well known that slightly exposure of nickel boride to the atmosphere produces significant oxidation to the active surface. In consequence $\mathrm{B}_{2} \mathrm{O}_{3}$ signal became higher. However when $\mathrm{Cr}$ was used as dopant metal the $\mathrm{BE}_{\mathrm{Ni}-\mathrm{B}}$ was higher than when $\mathrm{Zn}$ was used as dopant.

\subsection{TEM-SAED Analysis}

TEM pictures demonstrated that the particles of the fresh sample were spherical with the average size of about $50 \mathrm{~nm}$. nanopowders Figure 5(a)). It can be seen from the graph that all of the particles have spherical shape, fairly uniform size and smooth surface. Few small particles aggregate into secondary particles because of their extremely small dimensions and high surface energy. The sphericity-chain shape is the result of magnetic force and surface tension collaboration between the ultra-fine particles. Figure 5(b)) shows the corresponding selected area electron diffraction (SAED) pattern. It can be indexed to the reflection of $\mathrm{Ni}^{\circ}$ face centered cubic (FCC) structure in crystallography, this result also investigated by means of X-ray diffraction. Small particles cause a random distribution and cause the widening of diffraction rings that are made up of many diffraction spots, which indicates that the nanopowders are polycrystalline structure. Electron diffraction reveals that each particle is composed of many small crystal nuclei, which is convincing proof that the particles grow in an aggregation model.

\subsection{Magnetic Susceptibility Analysis}

As can be seen in Table 2, CrNiB has the highest magnetic saturation (magnetic susceptibility), even higher 


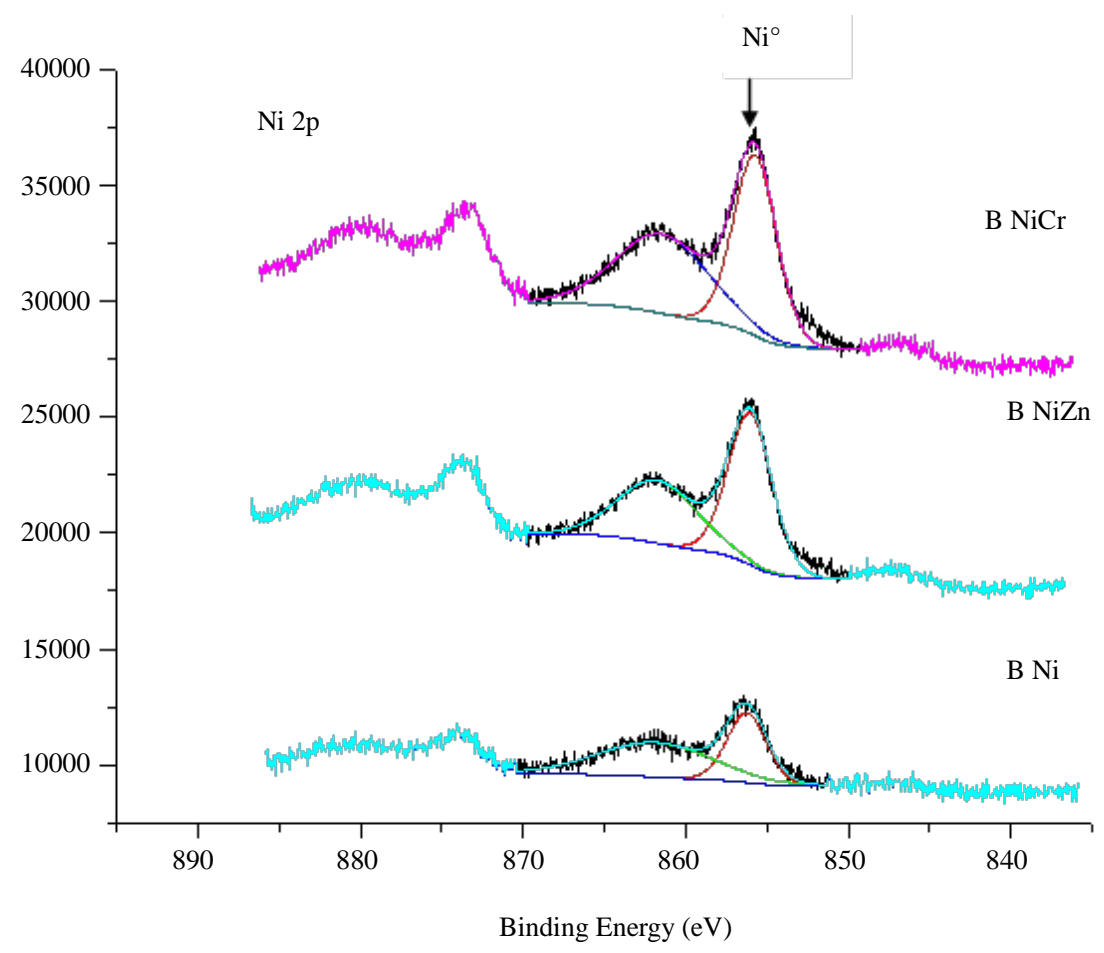

Figure 4. XPS Spectra for $\mathrm{NiB}$ and MNiB.

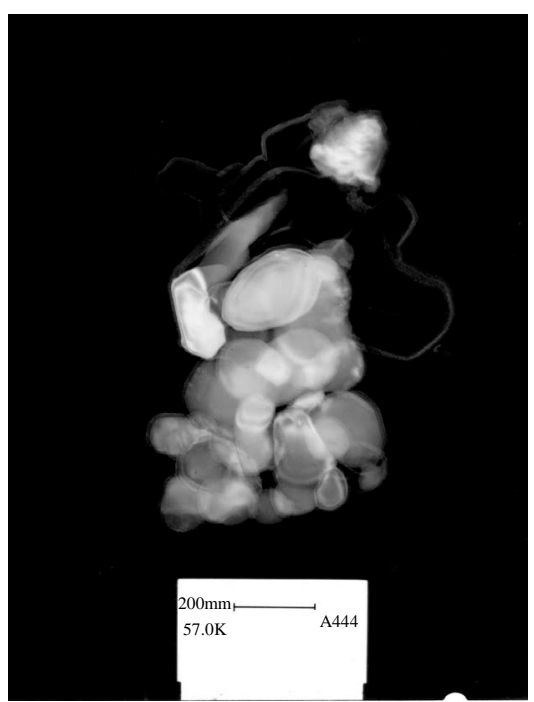

(a)

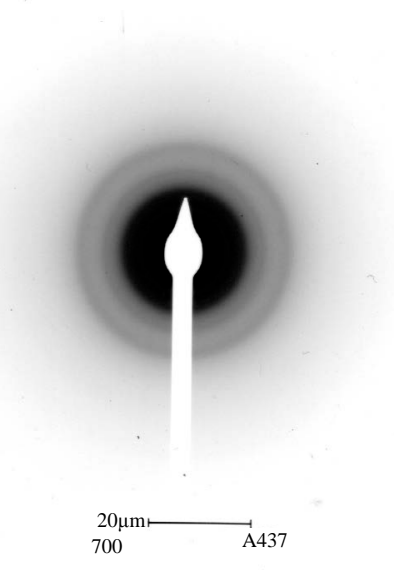

(b)

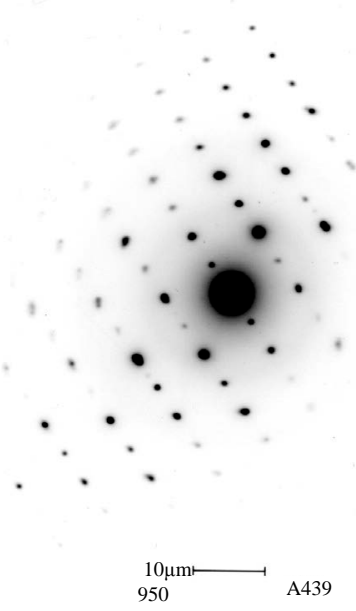

(c)

Figure 5. TEM micrograph (a) $\mathrm{NiB}$ amorphous structure including $\mathrm{Ni}^{\circ}$ crystal, (b) $\mathrm{SAED}$ pattern of $\mathrm{Ni}^{\circ}$, (c) $\mathrm{ED}$ shows $\mathrm{Ni}^{\circ}$ FCC structure.

than NiB. The magnetization [16] could be attributed to the positive holes in d-band of Ni and the magnetic moment is a measure of the occupancy of this holes. The electronic band theory of metals was applied [17] to explain the chemisorption changes and the catalytic activity of the alloys with transition metals. Changes in the composition of these alloys modify the energy density of electrons at the Fermi level. For this study the NiB and the bimetallic borides (MNiB) could be classify by the relation boron-metal in the metallic borides where the B forms a net of B-B bonds which gives place to a net produced by metal-metal bonds. In this kind of boride the interactions boron-metal are week, so the metallic net could be considered as an independent alloy of B. There- 
fore, the effect on the catalytic activity related to the metallic net composition can be analyzed.

The Fermi level of Ni falls slightly below the 3d-band and the magnetism is a consequence of the unpaired moment spin of about 0.6 holes per atom in the $\mathrm{d}$ band. The magnetic moment of $\mathrm{Ni}$ in the $\mathrm{NiB}$ is almost due to the unpaired spins of the electrons. The magnetization intensity in Bohr magnetons is practically equal to the number of holes in the d-band. With 0.6 vacancies per $\mathrm{Ni}$ atom in the d-band and a contribution of $\mathrm{N}$ electrons per atom of the added dopants, the number of holes (nh) could be calculated [18] with the following Equation (9):

$$
n_{H}=(0.6-x \Delta N) /(1+x)
$$

where $\Delta \mathrm{N}=$ (number of $\mathrm{Ni}$ electrons - number of dopants metal electrons) and $x$ is the number of dopants metal atoms per Ni atom. Figure 6 shows the relationship between magnetic susceptibility and the number of vacancies related to the number of electrons "s + d" and the content of the dopants metal. As can be noticed, a linear relationship is found.

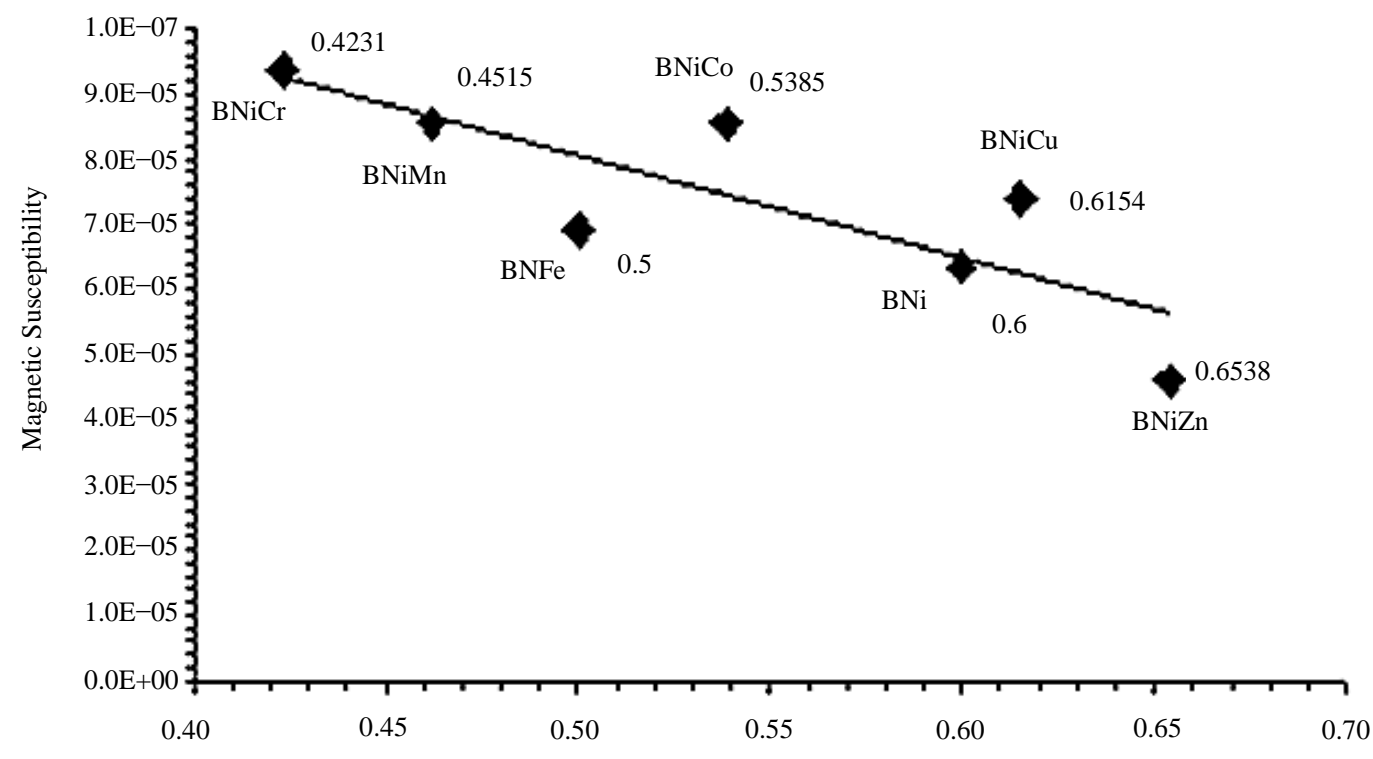

$\mathrm{N}^{\circ}$ of vacancies

Figure 6. Magnetic susceptibility of doped and non-doped nickel boride vs. number of holes of dopants metal.

\subsection{Activity Test for Hydrogenation Reactions}

Doped and non-doped nickel boride catalyst (MNiB, NiB) shows, in all cases, first order kinetic respect substrate and 0.7 order respect the hydrogen for glucose hydrogenation. As can be seen in Table 2 TOF values for $\mathrm{Cu}$ and Fe doped catalyst are the lowest. For both dopped catalysts, the proportion of metallic phase varied substantially in the case of the presence of doping as $\mathrm{Cu}$ and Fe. The adsorption was $14.0 \mathrm{~mol} \mathrm{H}_{2} / \mathrm{g}$ for $\mathrm{CuNiB}$ and $5.4 \mathrm{~mol} \mathrm{H}_{2} / \mathrm{g}$ for FeNiB. This shows an oxidative process since the hydrogen chemisorption measurements were carried out on the catalysts after the catalytic test [19]. The catalytic activity test is carried out in an aqueous medium which encourages rapid oxidation of metals, especially those having a high oxidation potential as in the case of these metals. Therefore for these catalysts (which contains $\mathrm{Cu}$, Fe metals as dopants), TOF values obtained are not comparable with the other results. This does not imply the values obtained rejected but simply to note that the metal area that is obtained is not the initial or "present during the performance of the catalytic test".

Table 2 shows that the presence of $\mathrm{Cr}$ even in low proportion produces a net increase of $52 \%$ in the catalytic activity. Actually the hydrogen adsorption capacity is almost the same $\left(40 \mathrm{~mol} \mathrm{H}_{2} / \mathrm{g}\right.$ to $39.9 \mathrm{~mol} \mathrm{NiB}$ and $\mathrm{H}_{2} / \mathrm{g}$ to $\mathrm{CrNiB}$ ). However when it comes to $\mathrm{Zn}$ as a dopant metal activity decreases by $50 \%$ compared to undoped. However hydrogen uptake was $33.68 \mathrm{~mol} \mathrm{H}_{2} / \mathrm{g}$, equivalent to $15 \%$ less than that of undoped boride. In the case of $\mathrm{Mn}$ as dopant $\mathrm{H}_{2}$ adsorption is $29.6 \mathrm{~mol} \mathrm{H}_{2} / \mathrm{g}$ and this represents a change in absorption of only $20 \%$, however 
the catalytic activity decreases by only $6 \%$ over the undoped. From these results it is seen that the presence of the dopant metals will not substantially change the hydrogen adsorption capacity of the catalyst and therefore this factor (Metallic area) cannot be responsible for the observed variations in catalytic activity [20].

Nitrobenzene hydrogenation reaction follows a kinetic of first order respect Nitrobenzene concentration and hydrogen, in agreement with data reported by Chen et al. [18]. The kinetic constant values in the glucose and in the nitrobenzene hydrogenation were obtained by a linear regression of the experimental data. For both hydrogenation reactions the effect of dopant metal in catalytic activity was the same. The presence of $\mathrm{Cr}$, as dopant metal, produce the higher activity value for both glucose and nitrobenzene hydrogenation process, as can be seen in Table 2. Section characterization showed that even when $\mathrm{Cr}$ is used as a dopant it is not detected in the metallic state or as oxide in the SEM-EDS and XPS studies. However in Table 2 it is clear that the TOF value is clearly higher than the NiB. Therefore we cannot explain increased promoter activity or action of the dopant by the existence of an oxide phase. The predominant phase in all catalysts (doped and undopedMNiBNiB) is metallic nickel and catalytic activity refers only to the possibility of dissociation of hydrogen on the metal surface of $\mathrm{Ni}^{\circ}$.

\section{Conclusions}

The borohydride reduction of these metal ions is a valuable way to produce nanoscale metal and metal boride, depending on potential reduction in non-aqueous media. The presence of metal oxide particles and boron oxide is a consequence of atmospheric exposure of solids in characterization studies. Results from whole characterization techniques show in all cases that a nickel metal phase is modified by dopant metal. However, all metal dopant in nickel boride preparation yielded the same composition, $\mathrm{Ni}^{\circ}$ and nickel boride, which is in agreement with the proposal reaction step mechanism.

In consequence, depending on the electronic nature of the co-metal added, the properties of the resulting material are modified producing the same effect on the catalytic activity in the glucose and nitrobenzene hydrogenation reactions. It means that the effect on the free activation energy is the same for both reacting systems. This behavior, as well as that observed in the magnetic susceptibility, is consequence of the modification in the electronic population of extended orbital of the metallic net.

\section{Acknowledgements}

The authors gratefully acknowledge the financial support received in the form of a research grant from the Committee of Researches of the National University of Salta (CIUNSa).

\section{References}

[1] Brown, C. (1970) Catalytic Hydrogenation. V. Reaction of Sodium Borohydride with Aqueous Nickel Salts. P-1 Nickel Boride, a Convenient, Highly Active Nickel Hydrogenation Catalyst. The Journal of Organic Chemistry, 35, 19001904. http://dx.doi.org/10.1021/jo00831a039

[2] Molvinger, K., Lopez, M. and Court, J. (1999) Asymmetric Reduction and Hydrogenation over Heterogenous Catalysts Prepared by Reacting Nickel-Boride with Norephedrine. Journal of Molecular Catalysis A: Chemical, 150, 267-273. http://dx.doi.org/10.1016/S1381-1169(99)00212-5

[3] Glavee, G., Klabunde, K., Sorensen, C. and Hadjipanayis, G. (1994) Borohydride Reduction of Nickel and Copper Ions in Aqueous and Nonaqueous Media. Controllable Chemistry Leading to Nanoscale Metal and Metal Boride Particles. Langmuir, 10, 4726-4730. http://dx.doi.org/10.1021/la00024a055

[4] Destefanis, H., Acosta, D. and Gonzo, E. (1992) Preparation of Metal Borides in an Aprotic System. Catalysis Today, 15, 555-564.

[5] Acosta, D., Ramirez, N., Erdmann, E., Destéfanis, H. and Gonzo, E. (2008) Glucose Hydrogenation over Nickel Boride Catalyst. Catalysis Today, 133-135, 49-55.

[6] Acosta, D., Destéfanis, H. and Gonzo, E. (1994) Lattin American Applied Research, 24, 2253-2256.

[7] Hopps, H. (1974) Chem. Eng. News (41), 52, Aldrich-Borane Inc., USA.

[8] Brown, H.C. (1960) Journal of the American Chemical Society, 82, 4703-4707.

[9] (1990) Accounts of Chemical Research, 23, 11.

[10] Schlegel, H. and Harris, S. (1994) Boron Trichloride. The Journal of Physical Chemistry, 98, 1178-1180. 
[11] Demitras, G., Russ, C., Salmon, J., Weber, J. and Weiss, G. (1973) Química Inorgánica. Prentice-Hall Internacional, Madrid.

[12] Wu, Z.J., Mao, X.K., Zi, Q., Zhang, R.R., Dou, T. and Yip, A.C.K. (2014) Mechanism and Kinetics of Sodium Borohydride Hydrolysis over Crystalline Nickel and Nickel Boride and Amorphous Nickel-Boron Nanoparticles. Journal of Power Sources, 268, 596-603. http://dx.doi.org/10.1016/j.jpowsour.2014.06.067

[13] Xie, S.H., Li, H.X., Li, H. and Deng, J.-F. (1999) Selective Hydrogenation of Stearonitrile over Ni-B/SiO 2 Amorphous Catalysts in Comparison with Other Ni-Based Catalysts. Applied Catalysis A: General, 189, 45-52. http://dx.doi.org/10.1016/S0926-860X(99)00243-4

[14] Kapfenberger, C., Hofmann, K. and Albert, B. (2003) Room-Temperature Synthesis of Metal Borides. Solid State Sciences, 5, 925-930. http://dx.doi.org/10.1016/S1293-2558(03)00117-1

[15] Li, H., Li, H.X. and Deng, J.-F. (2001) The Crystallization Process of Ultrafine Ni-B Amorphous Alloy. Materials Letters, 50, 41-46. http://dx.doi.org/10.1016/S0167-577X(00)00410-9

[16] Selwood, P.W. (1956) Magnetochemistry. Chap. 15, Intersience Pub. Inc., New York.

[17] Clark, A. (1974) The Chemisorptive Bond. Basic Concepts. Academic Press, New York \& London.

[18] Chen, Y.Z. and Chen, Y.N. (1994) Hydrogenation of Para-Chloronitrobenzene over Nickel Borides. Applied Catalysis A: General, 115, 45-57. http://dx.doi.org/10.1016/0926-860X(94)80377-3

[19] Singh, V., Ram, S. and Srinivas, V. (2014) Ferromagnetic Nickel Filled in Borate Shell by Controlled OxidationCrystallization of Boride in Air. Journal of Alloys and Compounds, 610, 100-106. http://dx.doi.org/10.1016/j.jallcom.2014.04.163

[20] Taghavia, F., Falamakic, C., Shabanova, A., Seyyedib, M. and Zareb, M. (2013) An Effective Method for Increasing the Activity of Nickel Boride Catalyst Nano-Particles in Hydrogenation Reactions: Low-Temperature Hydrogen Treatment. Applied Catalysis A: General, 453, 334-340. http://dx.doi.org/10.1016/j.apcata.2012.12.044 